\title{
A qualidade do atendimento ao turista: um comparativo entre duas cidades, São José da Coroa Grande (Pernambuco, Brasil) e Maragogi (Alagoas, Brasil)
}

\section{The quality of tourist service: a comparison between two cities, São Jose da Coroa Grande (Pernambuco, Brazil) and Maragogi (Alagoas, Brazil)}

\author{
Eduarda Semeão da Silva (SILVA, E. S. da); \\ Kaio Diego da Silva (SILVA, K. D. da) ${ }^{* *}$; \\ Josué Petrônio Quirino de Oliveira (OLIVEIRA, J. P. Q. de) **** $^{* *}$
}

RESUMO - Diante de um mercado competitivo, atender bem é fundamental, com turistas cada vez mais exigentes, superar suas expectativas se tornou uma obrigação dentro do turismo, com isso o objetivo desta pesquisa foi demonstrar a importância na qualidade do atendimento no setor turístico. No estudo se fez uma comparação entre duas cidades litorâneas em relação ao atendimento dispensado aos turistas, em São José da Coroa Grande e Maragogi, duas importantes cidades litorâneas de Pernambuco e Alagoas, ambas no Brasil. Para tanto neste estudo de caso, se utilizou a metodologia baseada em uma abordagem qualitativa, exploratória, e bibliográfica, para mostrar que a qualidade do atendimento poderia ser a principal ferramenta de satisfação para os clientes. Os resultados demonstraram uma superioridade no atendimento dispensado aos turistas na cidade de Maragogi, que junto com sua rede hoteleira e resorts estava oferecendo uma maior infraestrutura, assim como uma qualificação maior no atendimento, demonstrando que atender bem ao longo do tempo vai significar não apenas lucro, mas também desenvolvimento econômico.

Palavras-chave: Turismo; Qualidade no Atendimento; Fidelidade; Atendimento ao Turista.

ABSTRACT - In view of a competitive market, good service is essential, with tourists increasingly demanding, to exceed their expectations became an obligation in tourism service, then the purpose of this research was to demonstrate the importance of the quality of service in the tourism sector. In the study, it was made a comparison between two coastal cities in relation to the service provided to tourists, in São José da Coroa Grande and Maragogi, both important coastal cities from Pernambuco and Alagoas, Brazil. In this case study, the methodology was based on a qualitative, exploratory, and bibliographic approach in order to show that the quality of service could be the main

\footnotetext{
* Formação: Graduação em Administração pela Faculdade de Ciências Sociais dos Palmares (FACIP). Endereço físico para correspondência: BR 101, Km 186 Sul, s/n, Engenho São Manoel. CEP: 55540-000 Palmares - PE/Brasil. E-mail: eduarda_semeao97@ hotmail.com

** Formação: Graduação em Administração pela Faculdade de Ciências Sociais dos Palmares (FACIP). Endereço físico para correspondência: BR 101, Km 186 Sul, s/n, Engenho São Manoel. CEP: 55540-000 Palmares - PE/Brasil. E-mail: kaiiodiego6@gmail.com

Formação: Graduação em Administração pelo Centro Universitário UNIFAVIP, Mestrado em Administração pela Universidade Federal de Pernambuco (UFPE). Atividade profissional: Professor na Faculdade de Ciências Sociais dos Palmares (FACIP). Endereço físico para correspondência: BR 101, Km 186 Sul, s/n, Engenho São Manoel. CEP: 55540-000 - Palmares - PE/Brasil. E-mail: jptonyoliver@hotmail.com
} 
tool for clients' satisfaction. The results showed a superior service provided to tourists in Maragogi, which with its hotel chain and resorts was offering a greater infrastructure, as well as a greater qualification in the service offered, demonstrating that to serve well over time will mean not only profit, but also economic development.

Key words: Tourism; Quality in Customer Service; Fidelity; Tourist service. 


\section{INTRODUÇAO}

No mundo de produtos e serviços cada vez mais similares, clientes e parceiros cada vez mais exigentes, a diferenciação se tornou essencial à sobrevivência de qualquer negócio. A qualidade do atendimento então se tornou uma das principais ferramentas para gerar satisfação nas organizações modernas.

Com um mundo cada vez mais globalizado um turbilhão de mudanças traz preocupações em quase todos os segmentos do mercado. A sobrevivência das organizações passou a depender de fatores que impactam diretamente no seu dia a dia, o sucesso não depende apenas de um bom produto, mas de toda uma cultura voltada ao bom atendimento, isto é, os serviços e o funcionamento de toda empresa precisam estar vinculados a essa nova dinâmica de qualidade.

E para aqueles que trabalham com turismo não é diferente, cresce cada vez mais a expectativa do turista por serviços de qualidade superior, "para tornar-se competitivo mediante parâmetros de qualidade dos diversos elementos que compõem um destino turístico, exige desenvolver estratégias conjuntas e integradas" (RUIZ; AKEL; GÂNDARA, 2015). Ou seja, desde o atendimento numa recepção aos serviços de um restaurante, assim como serviços de infraestrutura de uma cidade para recebê-lo, tudo isso contribui para uma gama de serviços que trazem satisfação aos turistas e os fazem voltar e recomendar o destino visitado.

Muitas organizações têm investido em qualificação e motivação para os funcionários, quanto a diversos aspectos, porém no setor turístico este conceito é um dos mais importantes a serem difundidos, desde os grandes hotéis até as pequenas empresas que prestam serviços aos turistas ou aqueles que estão envolvidos indiretamente nestas atividades, todos devem propagar uma cultura de qualidade, de bom atendimento e encantamento, que sejam capazes de marcar no imaginário do turista aquela sensação de estar em casa.

Segundo o Serviço Brasileiro de Apoio às Micro e Pequenas Empresas $\operatorname{SEBRAE}^{1}$ (2014), a Confederação da Indústria Britânica apontou que $48 \%$ dos clientes estavam dando maior importância à qualidade dos produtos e serviços do que aos preços, isso demonstra que para muita gente é fundamental ter qualidade, e que nem

\footnotetext{
${ }^{1}$ http://www.sebraemercados.com.br/qualidade-do-atendimento-ao-turista/
} 
sempre o preço será o mais importante. O objetivo desta pesquisa então foi o de se fazer uma reflexão sobre qualidade no atendimento especialmente no setor turístico, quais os impactos, quais fatores seriam importantes, como os turistas estavam avaliando a qualidade no atendimento, especialmente os serviços de duas cidades litorâneas e turísticas dos estados de Pernambuco (São José da Coroa Grande) e de Alagoas (Maragogi).

\section{REFERENCIAL TEÓRICO}

Maximiano (1992, p. 112) menciona que "uma empresa é uma combinação de esforços individuais que tem por finalidade realizar propósitos coletivos”, já Pereira (2007) afirma que rever a forma como os serviços são prestados será uma crescente neste contexto de mudança em que a sociedade está inserida. Diante desta perspectiva "o turismo, na sua totalidade é uma atividade multidisciplinar e interdisciplinar, onde estão envolvidos diversos setores que o permeiam de maneira direta ou indireta, sendo serviços oferecidos que visam primordialmente atender os desejos e necessidades dos turistas” (MASCARENHAS; SOUZA, 2015). Ou seja, é necessário um esforço conjunto de diversos saberes a fim de proporcionar um adequado entendimento das variáveis envolvidas no turismo.

\subsection{CONCEITOS DE QUALIDADE}

Dias e Oliveira (2017, p. 2) observam que "a Qualidade Total concebe a busca da satisfação, não apenas do cliente, porém de todos os 'stakeholders' (entidades expressivas na vivência da empresa) e do mesmo modo da excelência organizacional da empresa." Ou seja, os funcionários também precisam estar inseridos na gestão de qualidade de uma empresa, pois funcionário feliz tratará bem os clientes, e com isso trará rentabilidade para a instituição, gerando um valor que será percebido pelos clientes como um processo voltado à qualidade e melhoria contínua (MASCARENHAS; SOUZA, 2015). 
Kotler, (2000, p. 70) discorre que "cliente altamente satisfeito, permanece fiel mais tempo, compra mais a medida que a organização lança produtos, custa menos para ser atendido do que novos clientes uma vez que as transformações são otimizadas". Portanto considera-se ser uma proposta de grande interesse à fidelização, satisfazer os clientes através de um atendimento de qualidade superior, um atendimento adequado, que respeite suas particularidades e crenças, seus anseios e desejos, não apenas suas necessidades.

Já Deming (1991, p. 78) aborda que: “A satisfação do cliente com relação a qualquer serviço ou item fabricado, medida por qualquer critério que seja, mostrará uma distribuição que varia desde a insatisfação extrema até altamente satisfeitos, exultantes". Ou seja, sempre será um diferencial quando um tratamento superior é colocado ao cliente, quando o melhor serviço, o melhor produto e o melhor atendimento convergem numa experiência capaz de gerar plena satisfação.

Las Casas (1999, p. 184) comenta que as empresas sempre devem buscar a melhoria contínua nos níveis de gestão de seus processos. Quando o cliente é o principal objetivo de uma empresa, a melhoria é uma fonte constante de satisfação, as organizações que não conseguirem entender esse conceito sofrem graves consequências em todos os seus processos, com isso fica claro que um atendimento de qualidade é uma importante estratégia mercadológica e também um diferencial para uma empresa (OLIVEIRA; HOLM, 2017).

Para Lacerda (2005, p. 20): "Qualidade é a filosofia de gestão que procura alcançar o pleno atendimento das necessidades e a máxima satisfação das expectativas dos clientes: usuários em todos os processos de uma empresa". Dentro desta perspectiva a qualidade do atendimento é uma ferramenta fundamental para uma boa gestão, seja numa pequena empresa, ou seja, numa organização pública que cuida dos cidadãos, essa filosofia deve ser a tônica de toda e qualquer gestão que esteja preocupada em oferecer resultados satisfatórios aos seus clientes.

\subsection{FIDELIDADE}

Kotler (2000, p. 71) observa que: "Para fortalecer a retenção de clientes, é essencial construir elevadas barreiras a mudanças. O melhor método, porém, é entregar 
um alto grau de satisfação ao cliente". Para ganhar a confiança e a fidelidade dos clientes é preciso ter cuidado com as mudanças bruscas, pois é muito fácil perder um cliente por preços muito elevados por exemplo. Para manter o cliente fiel a uma empresa e com alto nível de satisfação é preciso investir em todos os sentidos, desde descontos, preços adequados e acessíveis aos clientes, formas de pagamento, entregas, relacionamento, pós-venda, mas acima de tudo investir na qualidade do atendimento ajudará a fidelizar este cliente.

Considera-se que Kotler (2000, p. 58) esclarece adequadamente quando menciona que "somente empresas centralizadas nos clientes são verdadeiramente capazes de construir clientes, e não apenas produtos, e são hábeis em engenharia de mercados, não apenas em engenharia de produtos”. O sucesso de uma organização não é só pensar em produtos de qualidade, mas também pensar na qualidade dessa relação com clientes. Lacerda (2005, p. 19) comenta que: "O avanço do transporte e do comércio trouxe a possibilidade de os clientes fazerem comparações e, foi daí que o conceito de qualidade de produtos tangíveis começou a se firmar”. A partir de então os clientes contemporâneos não "buscam somente produtos ou serviços, mas sim experiências que proporcionem vivenciar emoções e experimentar sensações e situações que complementem sua vida cotidiana" (BOER; REJOWSKI, 2016, p. 7).

Diante deste contexto "um bom atendimento ao cliente está além do que um sorriso no rosto" (DALLEDONE, 2008, p. 63), lançando um olhar mais profundo sobre esta questão, Desantnich e Detzal $(1995$, p. 8) mencionam que não apenas clientes, mas funcionários, supervisores, gerentes e fornecedores, ou seja, a satisfação deve ser produzida para toda a comunidade. É preciso um entendimento maior sobre estas questões, mantendo a satisfação dos clientes externos e internos, dentro de uma dinâmica envolvente e crescente o que consequentemente afetará diretamente "a viabilidade e a lucratividade de uma empresa" (ABDALLA et al. 2013).

\subsection{QUALIDADE NO ATENDIMENTO}

Para Cobra (1997, p. 222): "Se o produto ou material vendido é de má qualidade, não há, realmente, serviços que possam dar satisfações ao consumidor”. A má qualidade do produto não será salva por um excelente atendimento. Por outro lado "um produto ou 
serviço com a mesma qualidade podem ser percebidos de formas distintas por pessoas diferentes" (MASCARENHAS; SOUZA, 2015, p. 427) é necessário então que os dois multipliquem esforços em uma direção, a qualidade.

Segundo Neves (2006, p. 75): “Acredita-se que, na luta pela sobrevivência, as organizações têm buscado oferecer qualidade em produtos e serviços. Diante da concorrência, o atendimento ao cliente é o principal fator de vantagem competitiva entre as organizações". A qualidade presente no atendimento é um fator que transcende o serviço ou produto e conquista o cliente de forma mais eficiente que qualquer outra estratégia.

Já Kotler (2000) aponta que: “O atendimento ao cliente envolve todas as atividades que facilitam aos clientes, o acesso às pessoas certas dentro de uma empresa para receberem serviços, respostas e soluções de problemas de maneira rápida e satisfatória". Atender bem é estar atento a processos, não apenas a venda, mas a todos os fatores envolvidos no ciclo de atendimento, afinal os detalhes fazem a diferença, pois "quando se excedem as expectativas, o serviço é percebido como de qualidade excepcional" (ABDALLA et al. 2013, p. 85).

Ganhará vantagem entre os seus concorrentes, aqueles que além de bons produtos têm em sua missão um bom atendimento. Com uma concorrência acirrada, produtos e serviços semelhantes apontam para um diferencial conhecido, mas ainda escasso entre muitas organizações que é a qualidade no atendimento. A qualidade dos produtos e serviços é importante, mas um atendimento de qualidade não apenas mantém a clientela, mas atrai novos consumidores (OLIVEIRA; HOLM, 2017), o que demonstra e deixa claro o posicionamento estratégico da qualidade no atendimento.

\section{METODOLOGIA DA PESQUISA}

A pesquisa de campo foi realizada em dois pontos turísticos do Nordeste Brasileiro, São José da Coroa Grande, cidade localizada em Pernambuco, distante 123 km de Recife sua capital, situada na extremidade meridional do Litoral Pernambucano. Centrada entre Recife e Maceió-AL, São José da Coroa Grande recebeu esse nome em alusão a "coroa grande" formada pelos imensos arrecifes de corais, bastante comuns na 
região, com população estimada em 2018 pelo Instituto Brasileiro de Geografia e Estatística - IBGE, em 21.004 pessoas. O município é repleto de belezas naturais e muito procurado por turistas na alta temporada. A segunda cidade escolhida foi Maragogi em Alagoas, situada na mesorregião do leste Alagoano, distando $125 \mathrm{~km}$ de Maceió, capital do estado. Com uma população estimada pelo IBGE em 2018 com 32.369 pessoas, com uma temperatura média de 27 graus Celsius, Maragogi é famosa por suas águas cristalinas e é conhecida como o "Caribe Brasileiro".

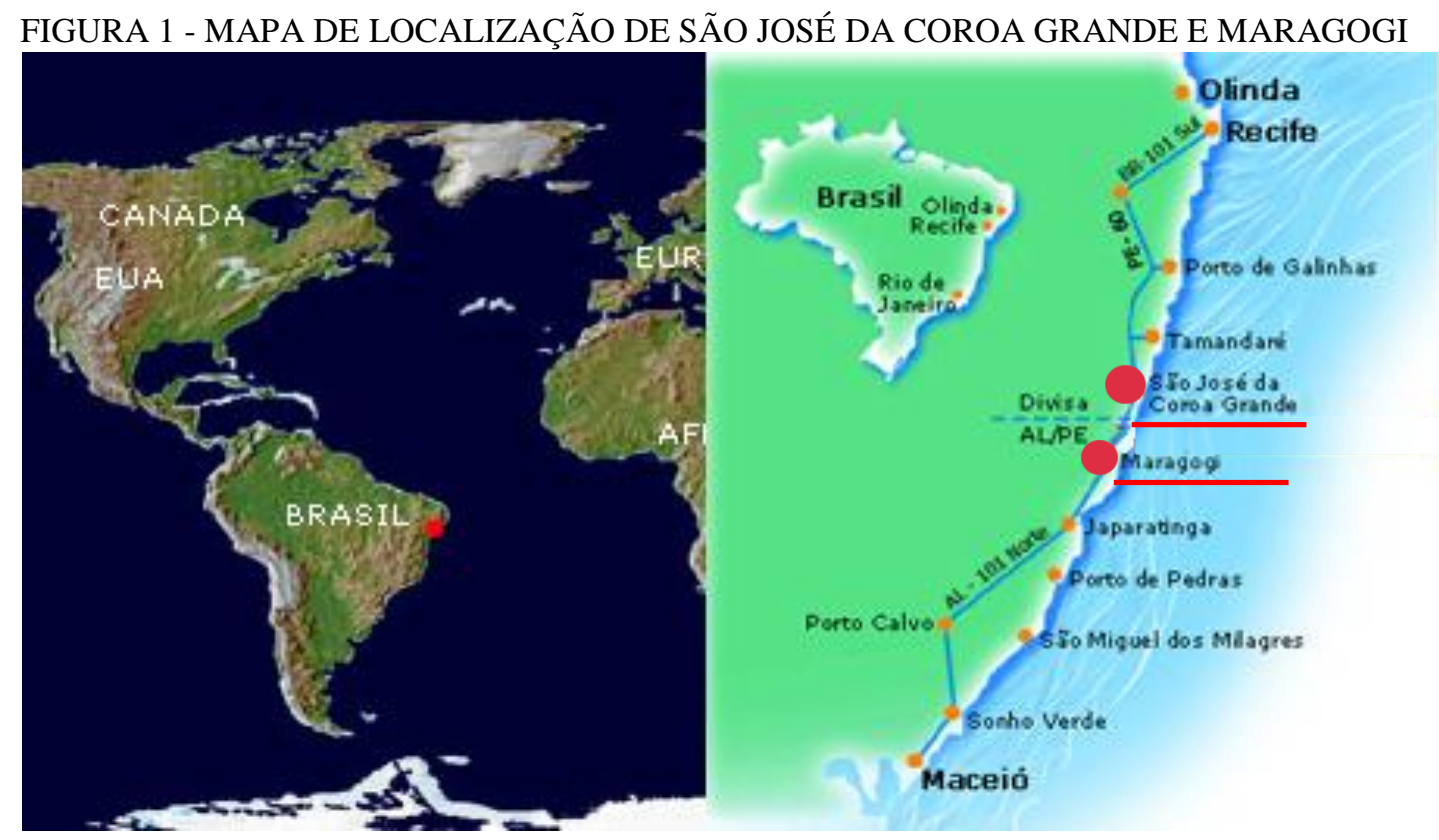

FONTE: Peroba Villa Hotel, 2018.

Além de serem duas cidades com grande fluxo de turistas e bastante representativas na conjutura local, a escolha delas se deu por conveniência já que os autores estavam nelas residindo. Isso facilitou o deslocamento e a pesquisa de campo, onde foram abordados um total de 200 turistas, dos quais 100 em Maragogi, Alagoas, Brasil e 100 em São José da Coroa Grande, Pernambuco, Brasil. A aplicação ocorreu nos períodos de 20 de janeiro de 2017 a 30 de março de 2017, abordando os turistas nos locais mais procurados, a fim de coletar informações sobre suas impressões sobre cada cidade escolhida.

Com isso a pesquisa referente a esse artigo teve por finalidade demonstrar como a qualidade do atendimento era importante para o crescimento das organizações, especialmente no turismo. Para alcançar tais objetivos foi estruturada dentro da 
abordagem qualitativa, pois "a pesquisa qualitativa preocupa-se, portanto, com aspectos da realidade que não podem ser quantificados, centrando-se na compreensão e explicação da dinâmica das relações sociais", ou seja: "trabalha com o universo de significados, motivos, aspirações, crenças, valores e atitudes, o que corresponde a um espaço mais profundo das relações, dos processos e dos fenômenos que não podem ser reduzidos à operacionalização de variáveis." (GERHARDT; SILVEIRA, 2009, p. 35).

Quanto aos objetivos é exploratória justamente por proporcionar uma visão geral, de tipo aproximativo acerca de determinado fato (GIL, 2008, p. 28) o que na verdade constitui a primeira etapa de uma investigação mais ampla. E quanto aos procedimentos se apresenta como um estudo de caso, "que se caracteriza pelo estudo profundo e exaustivo de um ou de poucos objetos, de maneira a permitir o seu conhecimento amplo e detalhado" (GIL, 2003, p. 58). Complementando, a partir de Yin (2005, p. 32) se trata de "um estudo empírico que investiga um fenômeno atual dentro do seu contexto de realidade". E também bibliográfica, pois teve seu referencial teórico construído a partir de material já elaborado e publicado como livros artigos científicos e revistas (LAKATOS; MARCONI, 2003).

\section{RESULTADOS}

A pesquisa de campo foi desenvolvida conforme exposto na metodologia, em duas cidades. Em São José da Coroa Grande o perfil do turista abordado se apresentou com $36 \%$ dos respondentes compostos por homens e $64 \%$ por mulheres, já desse total $38 \%$ apresentaram ensino médio, $4 \%$ ensino fundamental, $50 \%$ com ensino superior e $8 \%$ com pós-graduação ou superior, em sua escolaridade. Em Maragogi o quadro foi composto por $45 \%$ entre homens e $55 \%$ por mulheres, com $5 \%$ desse total com ensino fundamental, $40 \%$ ensino médio, $45 \%$ ensino superior e $10 \%$ com superior ou pósgraduação. Como as duas cidades são conhecidas e procuradas por suas praias, um dos pontos mais importantes diz respeito ao atendimento dispensado aos turistas nas praias, a qualidade do atendimento, a infraestrutura oferecida, disponibilidade e instrumentos necessários a boa estadia na cidade. Os resultados foram expressos em gráficos, conforme segue: 
GRÁFICO 1 - COM RELAÇÃO À QUALIDADE DO ATENDIMENTO NA PRAIA EM SÃO JOSÉ DA COROA GRANDE

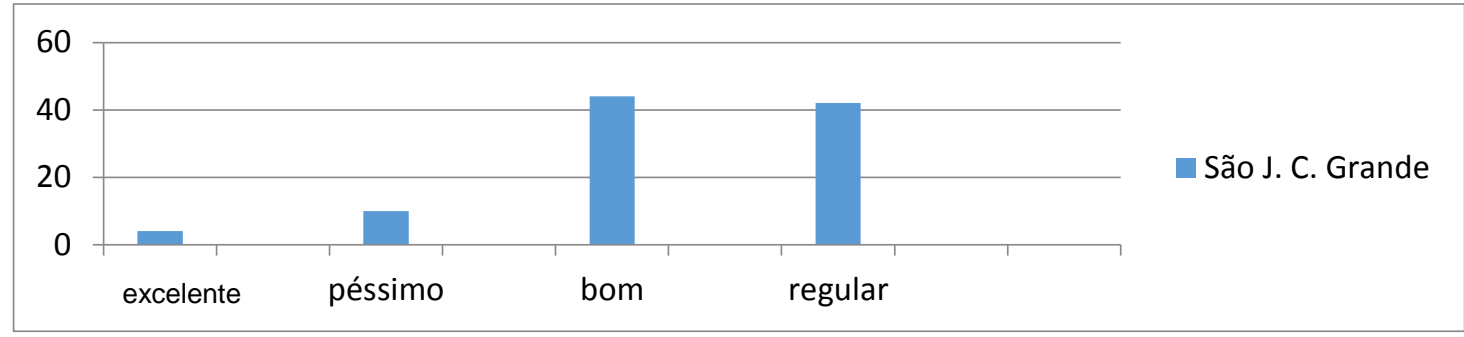

FONTE: Pesquisa de campo, 2017.

GRÁFICO 2 - COM RELAÇÃO À QUALIDADE DO ATENDIMENTO NA PRAIA EM MARAGOGI

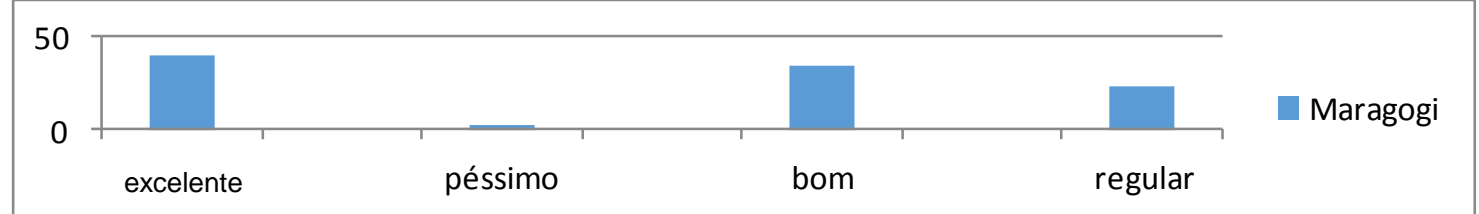

FONTE: Pesquisa de campo, 2017.

Os resultados demonstraram que apenas $4 \%$ classificaram como excelente o atendimento nas praias de São José da Coroa Grande (GRÁFICO 1), enquanto 44\% classificaram como bom, $42 \%$ como regular e $10 \%$ avaliaram como péssimo, apontando aqui uma necessidade urgente de investimentos em treinamentos e qualificação nesta cidade. Já em Maragogi (GRÁFICO 2) 40\% classificaram como excelente, 35\% como bom, $23 \%$ como regular e apenas $2 \%$ como péssimo, apresentando assim uma superioridade significativa do atendimento dispensado nas praias de Maragogi.

Já em relação ao tratamento dispensado aos turistas no comércio, o comparativo entre as duas cidades apontou que enquanto $4 \%$ dos turistas em São José da Coroa Grande (GRÁFICO 3) classificaram o atendimento no comércio como excelente, em Maragogi (GRÁFICO 4) esse ponto subiu para 37\%, enquanto em São José $62 \%$ classificaram como bom, em Maragogi foram $40 \%$ do total, em relação ao atendimento regular e péssimo, São José com 30\% e 4\% respectivamente ficando atrás de Maragogi com $3 \%$ e $20 \%$ demonstrando assim que também no atendimento dispensado aos turistas no comércio a cidade de Maragogi ficou num grau ligeiramente superior. 
GRÁFICO 3 - QUANTO À QUALIDADE DO ATENDIMENTO OFERECIDO NO COMÉRCIO - SÃO JOSÉ DA COROA GRANDE

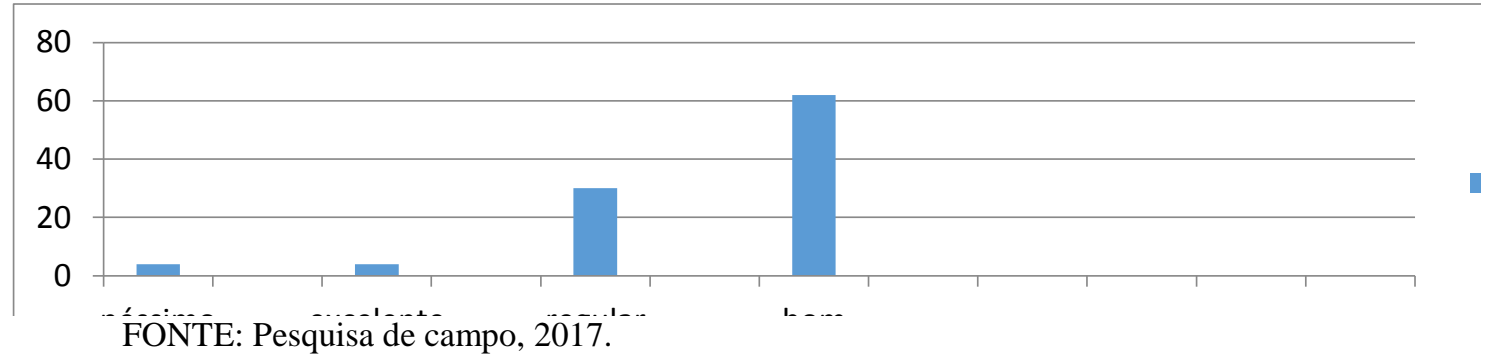

GRÁFICO 4 - QUANTO À QUALIDADE DO ATENDIMENTO OFERECIDO NO COMÉRCIO MARAGOGI

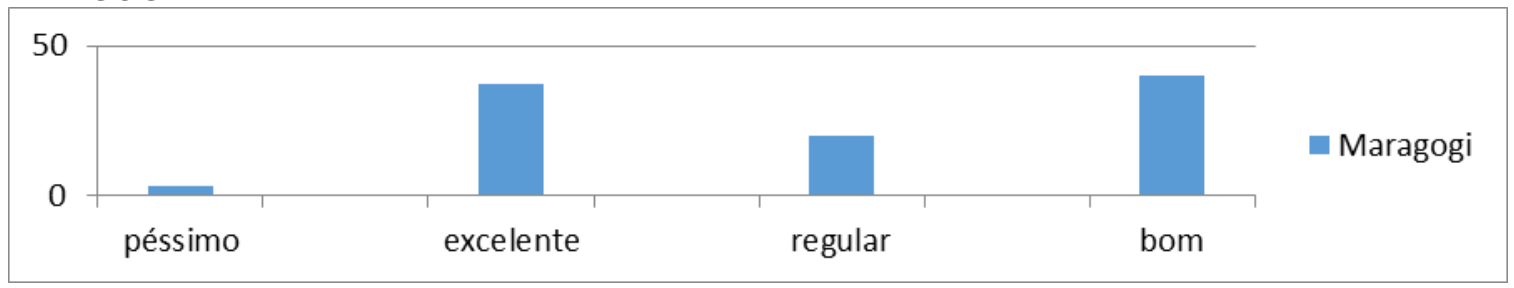

FONTE: Pesquisa de campo, 2017.

Um ponto fundamental para entendimento desta temática foi avaliar o mau atendimento que pode simplesmente afastar os turistas, os gráficos abaixo mostraram que:

GRÁFICO 5 - SE O TURISTA JÁ FOI MAL ATENDIDO - SÃO JOSÉ DA COROA GRANDE

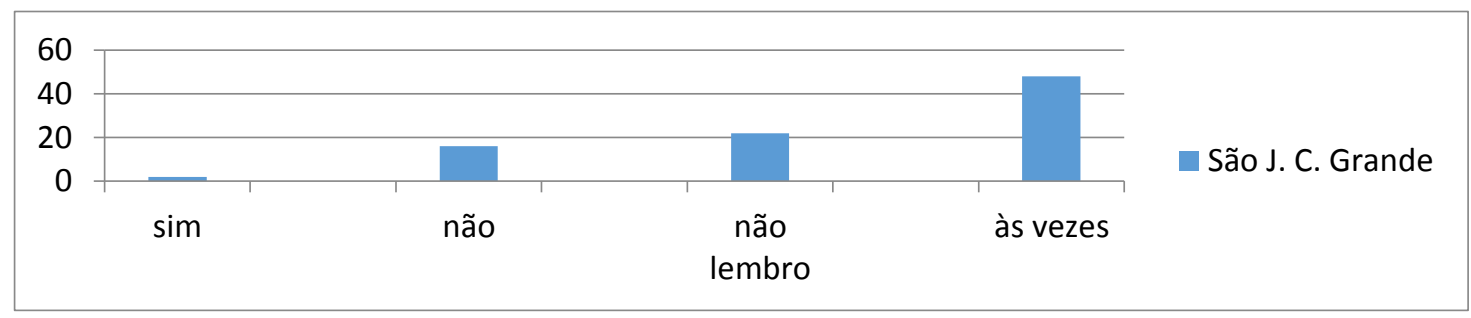

FONTE: Pesquisa de campo, 2017.

Quando questionados sobre se em sua estadia na cidade pesquisada os mesmos foram mal atendidos em algum momento, suas respostam apontaram que em São José da Coroa Grande (GRÁFICO 5) 2\% dos turistas responderam que sim, perceberam em sua estadia que realmente foram mal atendidos, para $16 \%$ a resposta foi que não, já $22 \%$ não lembravam e $48 \%$ relataram que às vezes se sentiram mal atendidos. 
GRÁFICO 6 - SE O TURISTA JÁ FOI MAL ATENDIDO - MARAGOGI

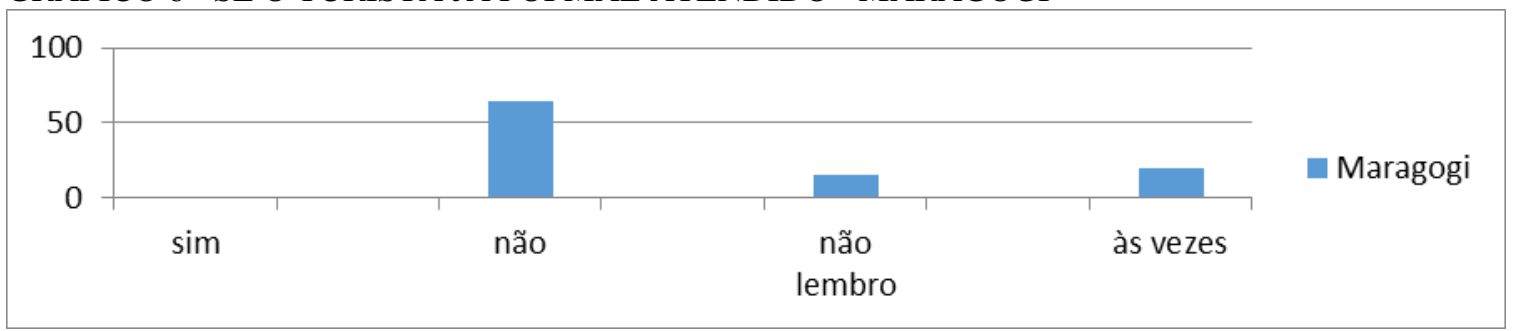

FONTE: Pesquisa de campo, 2017.

Por outro lado em Maragogi (GRÁFICO 6) 1\% afirmaram que sim, 64\% dos turistas assinalaram que não, $15 \%$ não lembrava e $20 \%$ marcaram que às vezes perceberam um mau atendimento. Demonstrando assim a importância do tema, pois são essas impressões que o turista leva para casa e transmite aos amigos e parentes.

Receber bem seja em um hotel ou até mesmo em uma cidade vai depender entre muitos fatores, de uma infraestrutura preparada para atender as necessidades dos clientes, que seja adequada e esteja de acordo com os padrões de qualidade esperados para que os clientes ou turistas, possam se sentir bem. Neste sentido no formulário se questionou como os turistas avaliavam a infraestrutura oferecida em cada uma das cidades.

GRÁFICO 7 - COM RELAÇÃO À INFRAESTRUTURA OFERECIDA PELA CIDADE - SÃO JOSÉ DA COROA GRANDE

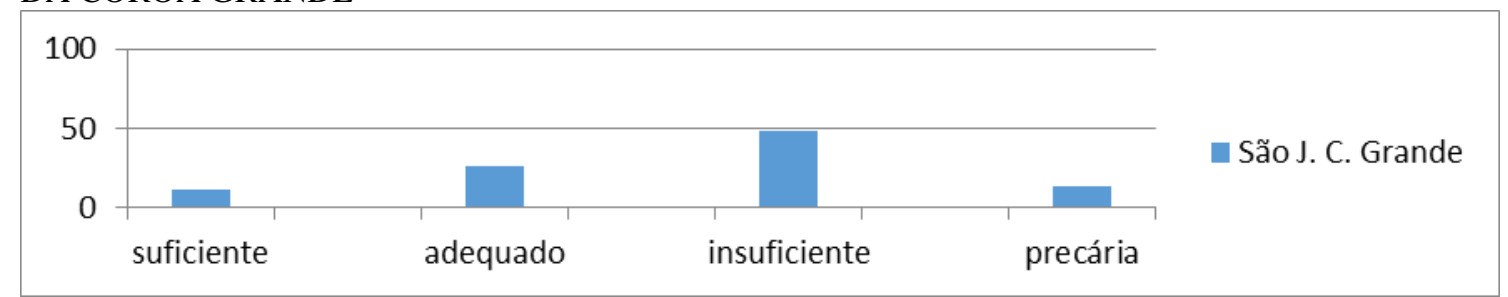

FONTE: Pesquisa de campo, 2017.

Em São José da Coroa Grande (GRÁFICO 7) 12\% dos turistas afirmaram que a infraestrutura oferecida na cidade era suficiente, já para $26 \%$ dos turistas abordados, a mesma era adequada, mas para $48 \%$ esta infraestrutura era insuficiente, e $14 \%$ ainda a apontaram como precária. Isso, demonstrando assim uma relevante informação para os gestores públicos atuarem nesta questão que incomodava tantos os turistas. 
GRÁFICO 8 - COM RELAÇÃO À INFRAESTRUTURA OFERECIDA PELA CIDADE MARAGOGI

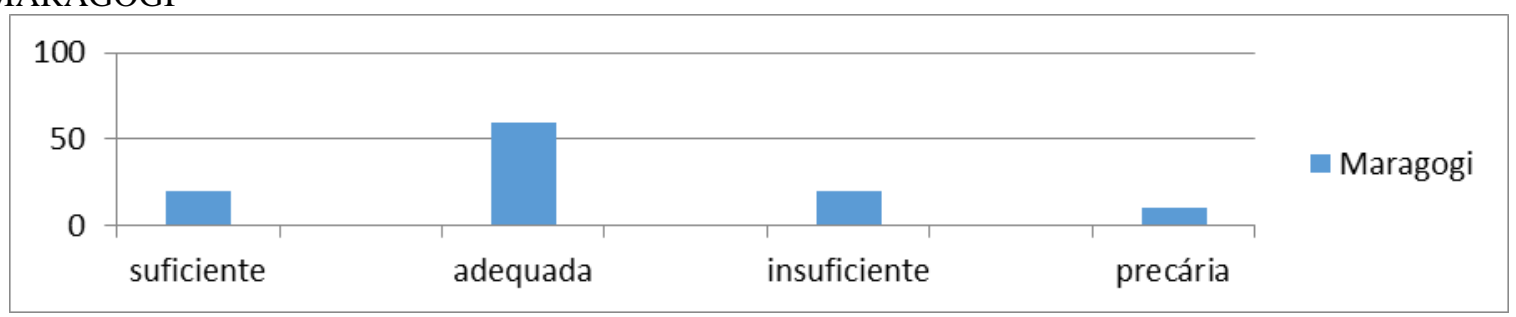

FONTE: Pesquisa de campo, 2017.

Em Maragogi (GRÁFICO 8) o quadro apresentado se tornou completamente diferente, demonstrando que $20 \%$ dos turistas consideraram a infraestrutura suficiente, enquanto $60 \%$ consideraram como adequadas e $20 \%$ classificaram como insuficiente e apenas $10 \%$ interpretaram como precária. Demonstrando assim que na percepção dos turistas abordados a infraestrutura estava bem melhor que a percepção dos turistas em São José da Coroa Grande.

Dentro deste contexto na pesquisa ainda se questionou os turistas sobre a qualidade e quantidade das hospedagens nas cidades. A opinião revelou que em São José da Coroa Grande, $2 \%$ dos turistas abordados as apontaram como excelente, já para outros $16 \%$ era suficiente, já $26 \%$ assinalaram que era adequada, enquanto que para a maioria, $50 \%$ as classificaram como insuficiente e outros $6 \%$ apontaram como precária. Enquanto em Maragogi se apresentou um quadro totalmente diferente onde $60 \%$ as classificaram como excelente, enquanto para $20 \%$ era suficiente, e para outros $25 \%$ adequada e apenas para $8 \%$ como insuficiente e $7 \%$ como precária. Um fator relevante para o entendimento destas respostas é que a cidade de Maragogi estava possuindo vários resorts, além de um maior número de hotéis e pousadas o que explicaria essa grande diferença na avaliação.

Outra questão importante abordada pelo formulário foi sobre quais fatores seriam essenciais para que o turista pudesse voltar novamente a estas cidades. As principais respostas apontaram para eventos e festas com 38\%, seguidos de eventos culturais e um bom atendimento com $20 \%$ cada opção, sendo esta a opinião dos turistas em São José da Coroa Grande. Por sua vez, em Maragogi 45\% dos turistas achavam essenciais os eventos culturais, seguidos de $15 \%$ para eventos e festas e $13 \%$ qualidade no atendimento, demonstrando assim a importância do atendimento para fidelização do destino turístico. 
E finalmente foi avaliada a nota numa escala de zero a dez que o turista daria para o atendimento de maneira global na cidade em que estava alojado? Em São José da Coroa Grande 64\% dos entrevistados responderam que o atendimento estaria entre as notas 6 e 8. Enquanto em Maragogi 65\% responderam que a qualidade do atendimento desta cidade estaria entre 8 e 10, confirmando assim que os detalhes fazem a diferença e são determinantes nas escolhas dos clientes, e solidificam a importância da qualidade do atendimento no turismo.

\section{CONSIDERAÇÕES FINAIS}

O objetivo da pesquisa foi realizar uma reflexão sobre a importância da qualidade do atendimento no turismo a partir de duas cidades litorâneas do Nordeste Brasileiro. Os resultados demonstraram a complexidade enfrentada pelas organizações, especialmente no turismo, afinal atender bem não é necessariamente difícil, mas tem sua complexidade e exige delicadeza frente aos resultados que podem depender de fatores subjetivos (MASCARENHAS; SOUZA, 2015).

Os resultados demostraram a importância destas questões, em São José da Coroa Grande com uma percepção mais negativa de toda a cadeia de atendimento, e em Maragogi, com uma percepção mais positiva. Ou seja, a percepção do turista acontece ao longo da prestação dos serviços e quando suas expectativas são superadas, os serviços são percebidos como de qualidade excepcional (ABDALLA et al. 2013). Esta sensível superioridade na avaliação em Maragogi - Alagoas poderia ser explicada pela presença de muitos resorts, que com maiores investimentos também desenvolvem uma estrutura de treinamentos e padrão de qualidade impostos por grandes redes de hotéis, traduzindo-se em uma percepção melhor no atendimento, atestando assim que investir em um atendimento de qualidade é uma importante estratégia mercadológica (OLIVEIRA; HOLM, 2017).

Com os resultados considerou-se ter obtido uma reflexão sobre a situação das duas cidades analisadas, quanto a esta questão, bem como a necessidade de um aprofundamento em pesquisas futuras a fim de explorar mais a temática em diversos aspectos como: quanto gastaria cada turista? Quais necessidades não estavam atendidas? 
O perfil do turista de cada cidade? Como ficaria a qualificação da rede hoteleira? Como ficaria a qualificação do comércio? E a profissionalização do comércio na praia? Considera-se que são questões de grande relevância para obtenção de respostas que merecem uma investigação por parte de suas prefeituras, secretarias de desenvolvimento econômico, sindicatos de comerciários e a sociedade local, para que a partir dessas informações passem a desenvolver políticas públicas específicas para resolver essa problemática. Santos, Alves e Gândido (2016) afirmam que 52,51\% dos turistas se deslocam a determinados destinos influenciados por amigos ou parentes que já tenham visitado tais locais. Ou seja, um turista quando bem atendido, volta para a cidade que está visitando, e o mais importante recomenda para amigos e parentes o que consequentemente impacta positivamente a economia local.

Portanto equacionar toda a dinâmica envolvida na qualidade do atendimento, especialmente no turismo é desafio muito grande para empresas, organizações e governos. Investir, qualificar e desenvolver ações para potencializar este atendimento é fundamental para a sustentabilidade de empresas e até para cidades que têm o turismo como vocação econômica. A percepção de qualidade em um atendimento é um grande diferencial que quando planejado eficientemente se traduz em satisfação do turista, ou seja, promove a volta ao destino visitado, faz recomendação, expõe publicação em redes sociais, faz mais gastos, inserindo mais dinheiro e movimentando a economia local. Por outro lado, quando esquecido ou negligenciado, se traduz em insatisfação, queixas, perdas de turistas, má recomendação e o consequente prejuízo a toda cadeia envolvida no atendimento. Afinal os clientes contemporâneos não buscam apenas produtos e serviços, mas experiências que proporcionem vivenciar emoções e experimentar sensações que lhe complementem sua vida cotidiana (BOER; REJOWSKI, 2016).

\section{REFERÊNCIAS}

ABDALLA, M. M.; ALTAF, J. G.; TROCCOLI, I. R.; NÓBREGA, K. W. P.; CRUZ, G. F. Lealdade aos meios de Hospedagem: um estudo com turistas de pousadas de Angra dos Reis. Revista Turismo e Sociedade, Curitiba, v. 6, n. 1, p. 79-103, 2013.

BOER, L.; REJOWSKI, M. Dimensões da Hospitalidade em um restaurante comercial. Revista Turismo e Sociedade, Curitiba, v. 9, n. 1, p. 1-23, 2016. 
COBRA, M. Marketing Básico. 4. ed. São Paulo: Atlas S. A., 1997.

DALLEDONE, J. Gestão de serviços: A chave do sucesso nos negócios. Rio de Janeiro: Senac Nacional, 2008.

DEMING, W. E. Qualidade: a Revolução da Administração. Tradução Chave de Clave Comunicações e Recursos Humanos. Rio de Janeiro: Marques Saraiva, 1991.

DESANTNICH, R. L; DETZEL, D. H. Gerenciar bem é manter o cliente. São Paulo: Pioneira, 1995.

DIAS, P. dos S. M.; OLIVEIRA, W. X. de O. Gestão de Qualidade Total. Anais... SEMINÁRIO DE PESQUISA, PÓS-GRADUAÇÃO, ENSINO E EXTENSÃO DO CCSEH, III-SEPE, Junho, 2017.

GERHARRDT, T. E.; SILVEIRA, D. T. Métodos de Pesquisa. Porto Alegre: UFRG, 2009.

KOTLER, P. Administração de Marketing: a edição do novo milênio. São Paulo: Prentice Hall, 2000.

LACERDA, F. A. B. Gestão da qualidade; fundamentos da excelência. Brasília: SEBRAE, 2005.

LAS CASAS, A. L. Qualidade Total em Serviços: Conceitos, Exercícios e Casos Práticos. 3. ed. São Paulo: Atlas, 1999.

LAKATOS, E. M.; MARCONI, M. A. Fundamentos de Metodologia Cientifica. 5. ed. São Paulo: Atlas, 2003.

LEBARBENCHON, A. F. ; BIESEMEYER, F. R. C. ; OLIVEIRA, M. S. C. ; JÚNIOR, Z. B. R. S. A qualidade no atendimento ao cliente no setor de serviços. 2001. Monografia (Pós-graduação em gestão da qualidade e da produtividade) - Fundação de Estudos Sociais do Paraná, Curitiba, 2001.

MASCARENHAS, R. G. T.; SOUZA, J. T. Qualidade percebida pelo paciente através dos serviços da hotelaria hospitalar: um estudo sobre a hospitalidade na área da saúde. Revista Turismo e Sociedade, Curitiba, v. 8. n 3, p. 419-445, 2015.

MAXIMIANO, A. C. A. Introdução a Administração. 3. ed. São Paulo, Atlas, 1992.

NEVES, A. R. Qualidade no atendimento: A chave para o sucesso pessoal e empresarial. Rio de Janeiro: Qualitymark, 2006.

OLIVEIRA, A. C. S.; HOLM, C. C. Agente de Viagens ou consultor de viagens? O perfil profissional da Agência Viajar Faz Bem de Campo Mourão. Revista Turismo e Sociedade, Curitiba, v. 10, n. 1, p. 1-21, 2017. 
PEREIRA, J. M. Curso de Administração Pública: foco nas instituições e ações governamentais. São Paulo; Atlas, 2009.

RUIZ, T. C. D.; AKEL, G. M.; GÂNDARA, J. M. G. Estudos de Competitividade Turística-Comparativo do Modelo de Dwyer e Kim e do Estudo de Competitividade dos 65 Destinos Indutores do Brasil. Revista de Turismo e Sociedade, Curitiba, v. 8, n. 1, p. 15-37, 2015.

SANTOS, J. G.; ALVES, A. P. F.; GÂNDIDO, G. A. Como receber o turista? A hospitalidade em destino turístico praieiro no nordeste brasileiro. Revista Turydes: Turismo y Desarrollo, n. 20, junio 2016.

YIN. R. K. Estudo de caso: planejamento e métodos. 3. ed. Porto Alegre: Bookman, 2005.

Recebido em: 19-12-2017.

Aprovado em: 18-01-2018.

Versão final para publicação: 01-12-2018. 